\title{
CERVANTES Y LA MEDICINA
}

A Cervantes le tocó vivir los comienzos difíciles del nacimiento de las ciencias modernas. Al papel importante que España representó durante el Medioevo, como depositaria del saber de Grecia y Roma, interpretándolo, comentándolo y esparciéndolo por Europa, siguió el rol nada glorioso, de oponerse a la entrada de los nuevos conocimientos científicos que ya empezaban a florecer en los demás países europeos. Y así, de innovadora, España se fue convirtiendo en renuente a cualquier innovación que no hubiese partido de las mismas raíces de la tradición. Esto no es de extrañar, pues es sabido con cuantas dificultades ha contado el progreso español, no sólo en el terreno puramente cultural y científico, sino también en el humano, en general, y médico, en particular.

En efecto, la Inquisición romana, tribunal de excepción, para reprimir la herejía, creado en el siglo XIII contra los albigenses e introducido en España desde los Reyes Católicos, cobra bajo Felipe II una implacable saña que alcanza, tanto a los erasmistas como a los protestantes y hasta a los místicos prelados. Durante su reinado se elabora, en 1559, el nuevo "Índice de libros prohibidos" que tiene por finalidad aislar a España de las nuevas corrientes de pensamiento, surgidas con libre despliegue creador en el campo de las ideas. Este Índice modifica radicalmente las condiciones de la vida intelectual española en prejuicio de aquel ambiente de libre reflexión y de alta especulación espiritual que el Humanismo erasmista había iniciado en los círculos universitarios españoles durante el reinado de su padre, Carlos V. Importar libros en idioma español sin licencia regia se constituye en crimen penado con la muerte y, para digno remate de esta política reaccionaria, está la pragmática de Felipe II reflejo de su intolerancia y fanatismo religiosos con la cual prohibía a los jóvenes el estudio en las universidades extranjeras, para evitar su contagio con las ideas discrepantes de los dogmas católicos. De tal modo, el pensamiento español se asfixia y se hunde en profundo atraso.

Este gran retraso se espeja también en el área de la medicina. En una época en que Flandes, por ejemplo, de facto colonia de España, contaba ya con los pioneros de la anatomía moderna, Andrés Vesalio y Pieter Paav, que revolucionaron la ciencia médica y no sólo conocían, sino también practicaban la trepanación, en la patria de Cervantes, los médicos solían aplicar aún métodos y medicamenots muy primitivos que consistían en purgas, sangrías y paños calientes. La sabiduría popular ha recogido tan lamentable estado de la ciencia médica en una serie de refranes. He aquí algunos de los más típicos:

"Médicos sin ciencia, largas haldas y poca conciencia"

"Médicos de Valencia, largas faldas y poca ciencia"

"Sangrías, lavativas y ventosas, y siempre las mismas cosas" 
Para ilustrarlo, mencionaré el conocidísimo caso del primogénito de Felipe II, príncipe don Carlos, quien a los dieciseis años se cayó una tarde de cabeza por una escalerilla. Fue recogido con una gran contusión en la sien izquierda y una parálisis en la pierna derecha. Curado de primera intención, fue sometido el mismo día al régimen de sangría y purga; al día siguiente le sacaron ocho onzas de sangre; el día sexto lo purgaron de nuevo sin poder cambiar su estado de insensibilidad. Creyeron conveniente los médicos dilatar la herida y dejar a descubierto el cráneo. Luego al punto se le declaró una erisipela.

Aunque reacio a pedir ayuda al sabio médico flamenco Andrés Vesalio, obligado por el empeoramiento de la salud de su hijo, el rey absolutista cedió por fin. Vesalio prohibió renovar las sangrías, pero los médicos españoles se opusieron a que se le curara la erisipela que se extendía por la cabeza, el pecho y los brazos, "porque se hubiera metido dentro", según arguían. De tal manera, se le purgó de nuevo con "tres onzas de jarabe de nueve infusiones." Todos los médicos de la Corte estaban reunidos alrededor del príncipe y combatían los consejos de Vesalio quien propuso una operación quirúrgica. Durante estas consultas, el embajador de Florencia, Nobili, escribía a Cosme de Médicis, su soberano: "Quien no lo haya observado, no puede formarse idea de la ignorancia de estos cirujanos."

Así como se habían apresurado a ampliar la herida de la cabeza, en lugar de adoptar la opinión de Vesalio, consintieron en emplear los ungüentos de un curandero árabe, llamado Pinterete. Pero, los ungüentos no dieron mejor resultado que las purgas: el delirio duraba ya cinco días; el rey, sentado a la cabecera de la cama y rodeado de once médicos, de pie en su presencia, sin poder emitir su dictamen si no eran por él interrogados, no tenía ya otra esperanza sino un milagro.

Según relata Cabrera de Córdoba, amigo de Cervantes y cronista de Felipe II, éste hizo traer a los frailes de San Francisco del monasterio de Jesús María, seminario de Santos, en procesión, el cuerpo del bendito Fray Diego y, puesto sobre el príncipe agonizante, lo volvieron a su capilla. Acto seguido, Vesalio le practicó la trepanación del cráneo extirpándole un quiste. El príncipe entró en convalecencia de inmediato, pudo levantarse a los treinta días, y poco después sanó. Sin embargo, el rey en su fanatismo religoso recalcitrante, apoyado en ello por sus médicos vernáculos, atribuyó la curación de su hijo al cadáver del fraile franciscano, es decir, a un milagro. Vesalio, empero, harto de aquel ambiente por todo extremo atrasado, sofocante y reaccionario, para librarse de él, pidió al rey el permiso para realizar un viaje a Jerusalén con el objeto de reconfortar su fe, a lo que Felipe II difícilmente podía oponerse. Y, una vez obtenido el permiso y abandonada la Corte española, nunca jamás volvió a ella.

Ahora bien, ¿tenía Cervantes interés y conocimientos médicos? Sin duda alguna, pues su mismo padre Rodrigo de Cervantes era médico y cirujano. En su biblioteca, en cuyos libros debió estar recopilado mucho de lo referente a su profesión, con toda seguridad el gran novelista, ávido de nuevos conocimientos —él mismo escribe en el Quijote que leía "hasta papeles rotos de las calles"- recibiría sus primeras impresiones médicas, que despertarían en él la afición por su estudio. 
De la lectura detenida de las obras cervantinas deducimos, que hay una inclinación a considerar la enfermedad como un resultado de la propia vida, un fenómeno de la naturaleza y no una intervención teológica, como es el caso, por ejemplo, de Lope de Vega.

Contacto doloroso con la medicina fue su herida en la batalla de Lepanto, el 7 de octubre de 1571, cuando formando parte de la escuadra de la Liga, fue herido en el pecho y en la muñeca de la mano izquierda que le quedó estropeada para el resto de la vida. Se cuenta que fue intervenido por el doctor Gregorio López, médico de Carlos V. Es probable que parta de ese suceso penoso el respeto de Cervantes por la figura del médico, respeto que muestra en todas sus producciones literarias.

Sus conocimientos de la medicina eran tales y tan profundos que Richard Blackmore, poeta inglés del siglo XVII y médico de cámara de Guillermo III, pidió consejo a su famoso colega Sydenham, apodado Hipócrates inglés, sobre qué libro debería leer para aumentar sus conocimientos profesionales, a lo que Sydenham respondió sin vacilación: "Leed el Quijote." En efecto, su obra cimera refleja muchas enfermedades magistralmente descritas, debido a los conocimientos médicos que tuvo el Manco de Lepanto, $\mathrm{y}$, sobre todo, debido a sus excepcionales dotes de observación. Las enfermedades en que demuestra más sus aptitudes médicas, son las típicas y más extendidas de su época, como la sordera, las cataratas, la tos y los reumas. $Y$, como para muestra basta un botón, he aquí uno referente a las cataratas: "Ya que el maligno encantador me persigue, y ha puesto nubes y cataratas en mis ojos... ha mudado y transformado tu sin igual hermosura y rostro en el de una labradora pobre..." (Parte II, cap. 10). Aparecen también muchas anormalidades patológicas, no muy bien definidas, que quedan encuadradas en un apartado que podríamos llamar "de los males humores", debiendo interpretar con este nombre los males producidos entonces. Así, por ejemplo, en el capítulo 25 de la primera parte, escribe: "Este es el sitio donde el humor de mis ojos acrecentará las aguas de este pequeño arroyo."

Cervantes confiere un valor enorme, el mayor de los métodos de investigación médica, a la observación directa de los síntomas de la enfermedad. El mal, según él, siempre se patentiza de alguna manera, o físicamente o en el comportamiento del enfermo. Se menciona también la neumonía y con más profusión que ésta, las diversas calenturas y el paludismo, fiebres terciarias o cuartanas, como se nombran en la obra que nos ocupa: “...y de allí a muy poco descubrieron muchos encamisados, cuya temerosa visión de todo punto remató el ánimo de Sancho Panza, el cual comenzó a dar diente con diente, como quien tiene frío de cuartana." (I, 19)

Tampoco el pulso puede ser olvidado en la sintomatología cervantina, ni la próstata, ni litiasis, la hepatitis, la muerte aparente. A la hepatitis se alude en el cap. 29 de la primera parte: "Les dijo [Sancho] como lo [a D. Quijote] había hallado, desnudo en camisa, flaco, amarillo." A la importancia del pulso, como indicio de enfermedad se hace alusión en el cap. 10 de la segunda parte: "...Que allí está hecho piedra mármol, todo turbado y sin pulsos." En el cap. 18 de la misma parte, se indica la litiasis renal: "Ciñóse su buena espada que 
pendía de un tahalí de lobos marinos; que es opinión que muchos años fue enfermo de riñones."

El genio de Cervantes supo ver las íntimas relaciones psicosomáticas que se producían en los hombres. Y supo exponerlas literariamente con tanto acierto que muchos de sus tipos han quedado como ejemplos en biotipología. Su aguda observación captó los rasgos diferenciales del carácter y su pluma ágil los mostró en pinceladas diestras y definitorias. Bástenos aquí también sólo un ejemplo de la descripción biotipológica. Tengo en la mente la que hace del ventero en el capítulo 2 de la primera parte: "Hombre que por ser muy gordo era muy pacífico."

Diagnosticó atinadamente en la mayor parte de los casos que nos relatan sus novelas, y, debido principalmente a su gran intuición, llegó a superar a muchos graduados en Salamanca y Alcalá de Henares, sobre todo en el terreno de la psicología, motivo por el cual muchos historiadores de la medicina lo consideran como uno de los precursores de la psiquiatría y la psicoterapia moderna. Efectivamente, es precisamente esta disciplina médica donde sus conocimientos destacan y brillan más, máxime si tomamos en consideración el hecho de que en aquel entonces la psiquiatría no existía aún como ciencia. No tuvo el novelista otras fuentes de información psiquiátrica que su propia y directa observación. Aprendió los secretos del alma humana en su trato continuo con los hombres, en los caminos que recorrió, en las ventas donde durmió, en la guerra y en las pacíficas villas provincianas. Algunos biógrafos cervantinos afirman con mucha razón que nuestro autor se preocupó por los locos y que visitó hospitales y manicomios y que intentó indagar los arcanos de la mente y del comportamiento científicamente. En El Quijote y también en otras obras cervantinas, aparecen diferentes formas de locura, con una sintomatología correcta y con el comportamiento propio de cada demente de su tipo. Así, figuran en sus libros: el loco D. Quijote, el loco Cardenio, el loco de Sevilla, el loco Lic. Vidriera y otros, cada uno con los síntomas inherentes a la clase de su enfermedad mental. A título de ejemplo, mencionaré el tipo de locura que afecta a su personaje principal — don Quijote- Esto viene a manifestarse en el episodio de la estancia del caballero andante en la mansión de don Diego de Miranda, alias el Caballero del Verde Gabán. Cuando éste preguntó a su hijo Lorenzo sobre lo que había sacado en limpio del ingenio del raro huésped, el hijo respondió: "Él es un entreverado loco, lleno de lúcidos intervalos." (II, 18) He subrayado el término "lúcidos intervalos", ya que muy contados médicos y ningún literato lo conocían a la sazón, con lo cual Cervantes se había anticipado casi cuatro siglos a la terminología sintomática de la psiquiatría moderna. Y Cervantes no se conforma con la descripción del tipo del enfermo mental o loco, que sea. Intenta, además, dar un diagnóstico, se preocupa por encontrar un remedio y toma precauciones para evitar el contagio, pues el gran novelista cree en el contagio de todas las enfermedades incluso en el contagio de la locura.

Ahora bien, ¿cuál fue la posición de Cervantes con respecto a los médicos? Si el autor del Quijote respeta mucho la medicina como ciencia que alivia y cura el dolor humano, no ocurre lo mismo en cuanto a su postura frente a los médicos. Estos han tenido en su abru- 
madora mayoría muy mala fama, como lo asenté al principio de este ensayo. Por ello, la figura del médico aparece la mayoría de las veces criticada duramente y siempre tratada con cierto escepticismo por parte de los literatos contemporáneos suyos. El que más los fustigaba fue Francisco de Quevedo. En uno de sus escritos escribe: “... todos enferman del exceso o destemplanza de humores; pero lo que es morir, todos mueren de los médicos que los curan." Cervantes, empero, consecuente con su profundo humanismo y culto a la verdad, era más justo; por ello, vapulea a los malos, pero pone por las nubes a los buenos. Veamos algunos textos que lo corroboran. "En verdad, señor, que soy el más desgraciado médico que se debe hallar en el mundo, en el cual hay físicos [médicos] que, con matar al enfermo que curan, quieren ser pagados de su trabajo que no es otro sino firmar una cedulilla de algunas medicinas..." (II, 71), dice Sancho durante la plática con don Quijote regresando a su aldea. En otra parte escribe el novelista, que a la mujer del labrador natural de Miguelturra que se presenta ante Sancho-Gobernador, se la "mató un mal médico, que la purgó, estando preñada" (II, 47), palabras que aluden al caso real ocurrido a la reina Isabel de Valois, la tercera esposa de Felipe II. Ésa, según la carta del ya mencionado embajador de Florencia en España, dirigida a su monarca, la han matado los médicos "habiéndola sangrado por los pies", es decir, cuando más necesitaba de energías y buena alimentación.

El doctor Pedro Recio de Agüero, agregado al gobierno de Sancho Panza en la Ínsula Barataria, es una perfecta caricatura de un médico charlatán. Cervantes lo trata con ironía escribiendo que tenía el "grado de doctor por la Universidad de Osuna" — pequeña universidad de provincia que, además, carecía de la facultad de medicina- y era nombrado para maltratar a Sancho, quien fastidiado por las privaciones alimentacias a que lo somete, lo corre diciendo que "matar un mal médico verdugo de la república" es hacer servicio a Dios. (II, 47) Pero, al mismo tiempo, ensalza por labios del mismo personaje, a los buenos médicos. Así, en la misma disputa con el doctor Pedro Recio define su política respecto de los médicos: "No me ha de quedar médico en toda la ínsula, a lo menos de aquellos que yo entienda que son ignorantes; que a los médicos sabios, prudentes y discretos les pondré sobre mi cabeza y los honraré como a personas divinas." (II, 47).

También los malos cirujanos reciben el rapapolvo de la aguda pluma cervantina, tildándolos desdeñosamente de "sacapotras". Don Quijote, por ejemplo, responde colérico a Cardenio, cuando éste habla del amancebamiento de la reina Madásima: "...y no se ha de presumir que tan alta princesa había de amancebar con un sacapotras.” (I, 24)

Si los médicos en su gran mayoría eran ignorantes y mal preparados, los boticarios que también tenían mucho que ver con la salud de la gente y su bienestar físico, han convertido su profesión en mero comercio. Guiábales exclusivamente el interés de obtener los mayores ingresos pecuniarios para enriquecerse, sin importarles el bien o el mal que estaban causando a los que confiados en su honradez y rectitud, acudían a ellos. Con sus embustes y engaños, vendiendo gatos por liebres, ponían en peligro la salud de la población. La sabiduría popular española refleja fielmente la corrupción de los boticarios en los refranes que cito a continuación: 
"Cuando el doliente va a la botica, una persona pobre y dos ricas"

"En la cuenta del boticario, por más que se quite y requite, siempre se gana el envite"

"Donde no hay boticarios ni médicos, los hombres se mueren viejos"

Y el Lic. Vidriera, protagonista de la novela ejemplar del mismo nombre, arremete contra los boticarios cuando uno de éstos le pide la explicación de su observación según la cual, ellos tienen un oficio salutífero, si no fuesen enemigos de sus candiles. Y Vidriera le responde con presteza: "Esto digo, porque en faltando cualquiera aceite, lo suple el del candil que está más a mano...". Además, decía que había "boticarios que, por no decir que faltaba en su botica lo que recetaba el médico, por las cosas que les faltaban ponían otras que a su parecer tenían la misma virtud y calidad no siendo así; y con esto, la medicina mal compuesta obraba al revés de lo que había de obrar la bien ordenada."

Según parece, los boticarios buenos no figuran en la obra cervantina, de lo cual se podría deducir que no existían. Pienso, sin embargo, que sí los había también, pero eran tan pocos que eran más bien moscas blancas y, por ende, Cervantes no los menciona.

\section{Bibliografía}

Astrana Marín, Luis: Vida ejemplar y heroica de Miguel de Cervantes Saavedra, Madrid, 1948-58.

CABRera DE CORdoba, Luis: Felipe II, Rey de España, Madrid, 1876.

FORNERON, Henri: Histoire de Philippe II, Paris, 1880-82.

Gachard, Louis Prospère: Don Carlos et Philippe II, Paris, 1863.

LÓPEZ MÉNDEZ, Harold: La medicina en El "Quijote", Madrid, 1969.

MARTÍNEZ KLEISER, Luis: Refranero general ideológico español, Madrid, 1953.

OsTERC, Lúdovik: El pensamiento social y político del Quijote, 3. ${ }^{\mathrm{a}}$ ed., México, 1988.

La verdad sobre las Novelas ejemplares, México, 1995.

\section{CERVANTES IN MEDICINA}

Cervantes je živel v času, ko so se naravoslovne vede $v$ Evropi šele rojevale. Tudi medicina. Ta je bila v Španiji v dobi vladanja Filipa II. izrazito zapostavljena, čeprav je drugod, tako $\checkmark$ Italiji, pa tudi $v$ tedaj španski Flandriji, doživela pomemben razvoj.

Ne gre pozabiti, da je bil Cervantes sin zdravnika. Znano je tudi, da je bil v bitki pri Lepantu ranjen in mu je poškodba zapestja leve roke ostala vse življenje. Iz njegovega literarnega dela pa je razvidno, da zdravnike spoštuje, da sam pozna simptome različnih bolezni in ceni predvsem to, da zdravnik čimbolj natanko opazuje bolezenske znake. Več opazk o psihičnem stanju posameznih oseb postavlja Cervantesa za nekakega predhodnika moderne psihoterapije. Cervantes pa ne kaže nobene naklonjenosti do lekarnarjev, pa tudi ne do šarlatanov, kot je to gotovo bil doktor Pedro Recio de Agüero (2. del, 47. poglavje), ki uteleša karikaturo šarlatana: njegova naloga je samo ta, da prepoveduje Sanču-guvernerju vsakršno hrano, češ da mu utegne škoditi. 